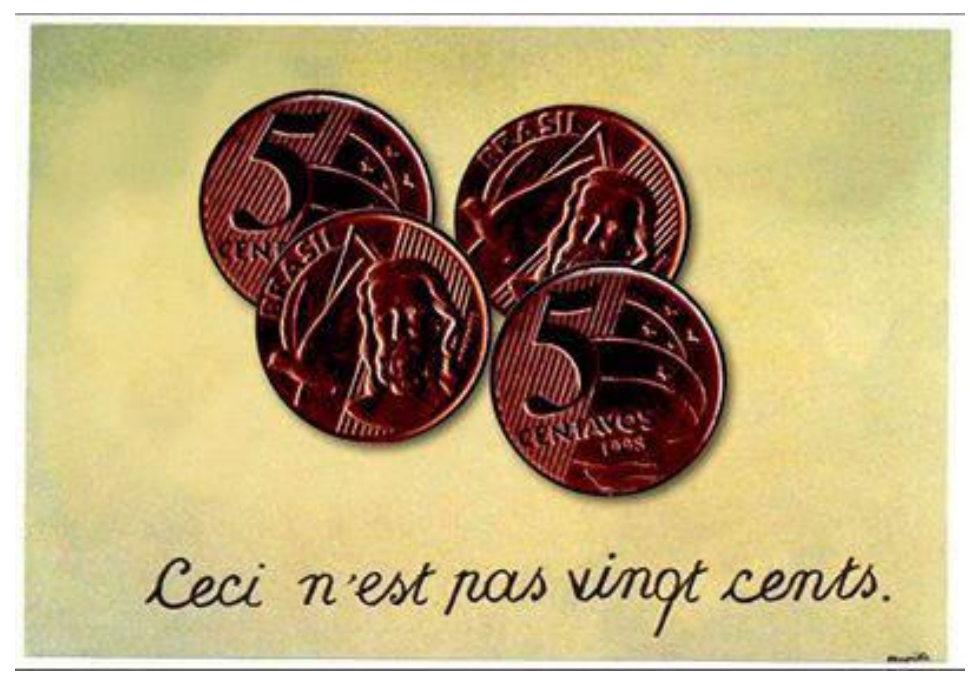

\title{
Por uma teoria do sujeito intervalar na experiência com a tela escura
}

By an interval's subject theory in the experience with the dark screen

\section{Resumo:}

José Isaías Venera ${ }^{1}$

ORCID: https://orcid.org/0000-0002-9220-446X

Neste artigo, desenvolve-se a noção de sujeito intervalar a partir das experiências contemporâneas com os dispositivos móveis de acesso à internet. A investigação inicia com uma imagem que circulou nas redes sociais da internet durante os protestos de junho de 2013, por meio da qual são feitas relações, sobretudo, com outras duas imagens de dois períodos históricos, sendo uma analisada por Michel Foucault (1999) e outra por Gilles Deleuze (2007). O modo como Foucault e Deleuze se apropriam de obras de arte para investigar a formação de novos campos de visibilidade permite também a análise sobre a emergência de uma outra relação com as imagens e com a qual é desenvolvida a noção de sujeito intervalar.

Palavras-chave: Sujeito intervalar; Representação radical; Agenciamento coletivo de enunciação.

\section{Abstract:}

In this article, the notion of interval subject is developed from the contemporary experiences with the mobile devices of access to the internet. The research is based on an image that circulated on Internet social networks during the protests of June 2013, in which relations are made especially with two other images from different historical periods, one of which is analyzed by Michel Foucault (1999) and another by Gilles Deleuze (2007), but each as an event that expresses new processes of subjectivation. The way how Foucault and Deleuze appropriated works of art to investigate the formation of new fields of visibility also allows the analysis of the emergence of another relation to the images in which the notion of the intervalar subject is developed.

Keywords: Subject interval; Radical representation; Collective agency of enunciation.

\footnotetext{
${ }^{1}$ Doutor em Ciências da Linguagem pela Unisul. Professor dos cursos da área da comunicação da Univille e da Univali. E-mail: j.i.venera@gmail.com
} 


\section{Introdução}

O acontecimento junho de 2013 no Brasil deixou em aberto uma imagem difusa, que não se deixa ver com nitidez. Esse é o ponto central para se falar em acontecimento junho de $2013^{2}$, o que escapa aos esquemas de interpretação, deixando a linguagem em vertigem. Articula-se a noção de sujeito intervalar a partir das novas experiências com os dispositivos móveis de acesso à internet, com destaque para smartphones e iphones, tendo como problema de investigação a emergência de coletivos que saem às ruas mobilizados por encontros em redes sociais da internet, dos quais figuras de lideranças perdem sentido nos arranjos rizomáticos.

O estudo parte de uma imagem que circulou durante os protestos de junho de 2013 e sua relação direta com a pintura surrealista A traição das imagens (1928/1929), de René Magritte. A nova imagem, Ceci n'est pas vingt cents, é analisada como acontecimento dos protestos. O modo como a imagem se constitui, como ela circulou na internet e a prática de acesso à imagem indicam um novo campo de visibilidade, por meio do qual novos processos de subjetivação se formam.

Para dar conta desta análise, operam-se, sobretudo, as noções de agenciamento coletivo de enunciação, de Gilles Deleuze e Félix Guattari (1997), e da representação radical (ou da representação da representação), de Michel Foucault (1999), como caminho teórico para investigar a emergência de um novo processo de subjetivação, por meio do qual é desenvolvida a noção de sujeito intervalar.

\section{O sujeito diante da imagem}

Quatro moedas de cinco centavos surgem numa pintura digital. O internauta lança seu olhar às moedas, mas, como um imã em atrito, é movido à frase abaixo que integra a própria imagem: Ceci n'est pas vingt cents. Despercebido, como em um ato falho, talvez não traduza a frase, mas entre as moedas e a escrita-desenho, o olhar se abre para o internauta liberar seu volume na esteira dos eventos de junho de 2013. Um sistema sutil dá às imagens as condições de visibilidade, como um signo que manifesta as regras estruturantes do que se diz, do que se sabe e do volume que se pode liberar. Mas haveria um olhar a mais - como um resto que escapa aos eventos?

2 Parte do conteúdo deste artigo integra a tese "Da cólera ao acontecimento junho de 2013: do que escapa à representação em Deleuze e Lacan". 
A imagem circula entre tantas outras nos protestos de junho de 2013, quando o Brasil foi sacolejado de Norte a Sul por uma avalanche de manifestações. Tão rapidamente quanto uma onda de acontecimentos, a imagem se desvanece nas telas escuras das mídias digitais, como "um rosto na areia da praia" (FOUCAULT, 1999, p. 536) varrido pelo vento. Será o prelúdio de um novo regime de visibilidade?

$\mathrm{Na}$ assinatura do autor, o nome Magritte reforça o lastro com a pintura Traição das imagens (1928/1929), mas se decompõe tão rápido quanto os pixels que formam a imagem digital. Ter-se-ia neste jogo de representação a função autor desconstruída sem ancorar num indivíduo representante da posição de autoria?

A nova imagem circula como um rastro do que, no passado, questionou o jogo da representação. Ceci n'est pas vingt cents estende os limites da própria linguagem da obra do pintor belga René Magritte conhecida como "Isto não é um cachimbo" (cujas condições de possibilidade para emergência da pintura surrealista estavam dadas à sua época), como se uma rede de sensações (cores, formas e efeito de texturas etc.) e de sentidos (do enunciado que integra a pintura) se formasse a partir da nova imagem, desde o gesto criativo aos compartilhamentos em redes sociais da internet.

Figura 1: Imagem que circulou em diferentes redes sociais da internet

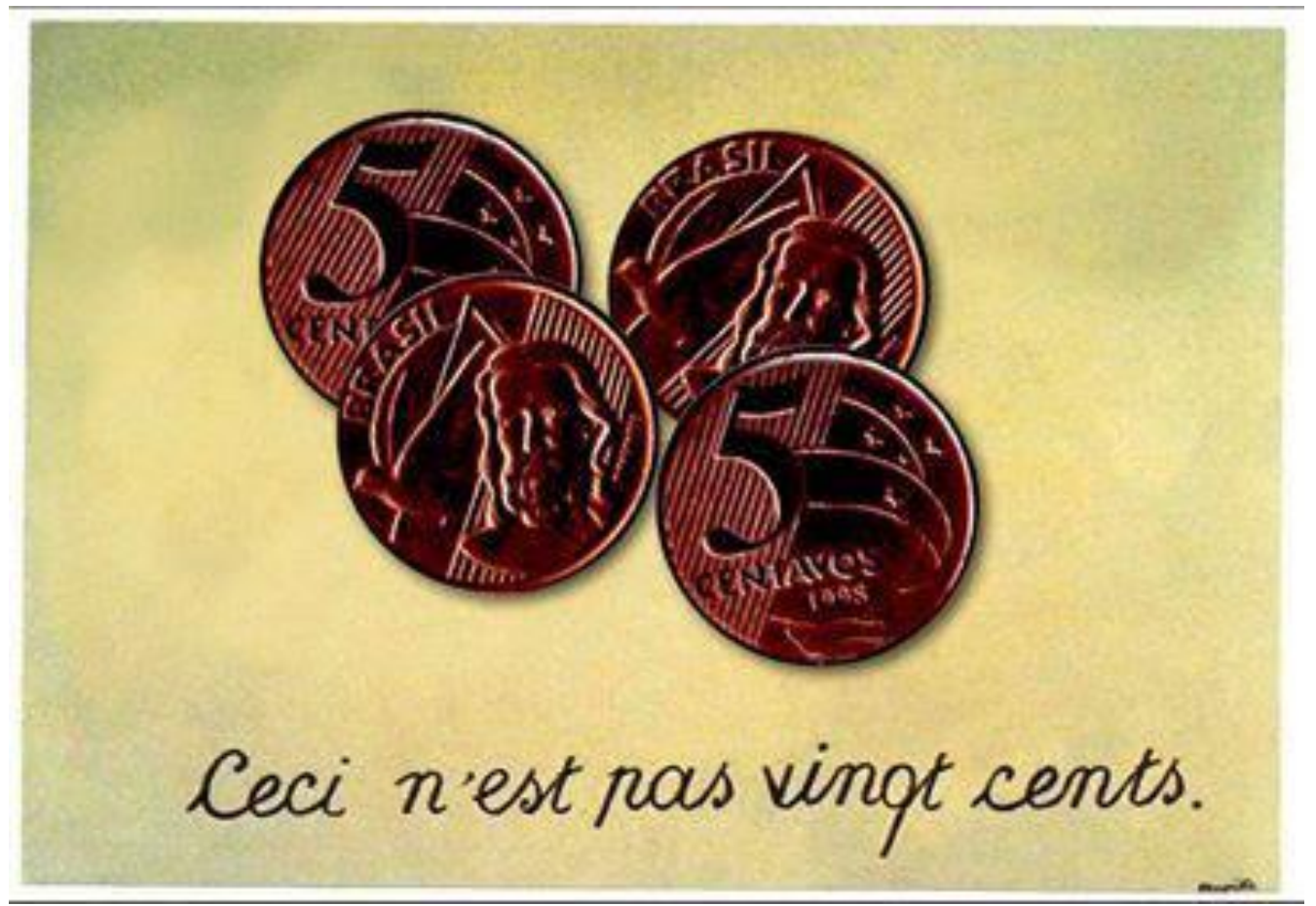

Fonte: http://blogdas30pessoas.blogspot.com.br/2013/06/vinte-centavos.html 
Apesar de figurativa, a tensão entre figura e texto força para um processo "puro figural" (DELEUZE, 2007), já que o enunciado nega o figurativo como se quisesse desautomatizar o significado de uma imagem, forçando-a para aquilo que de fato a constitui - a sua materialidade pictórica e digital; já que a imagem se compõe por pixels. De fato, a pintura de Magritte e da nova imagem (como se pode observar na Figura 1) estaria a meio caminho daquilo que o teórico formulou, a partir das pinturas de Bacon, ao exaltar o desforme, porque "não tem nem modelo a representar, nem história a contar" (DELEUZE, 2007, p. 12). A meio caminho, já que, enquanto semelhança, a imagem do cachimbo (bem diferente das imagens de Bacon) é realista, e o enunciado afirma este realismo, mesmo que para negá-lo, abrindo uma tensão entre ambos.

O "não" - Isto não é um cachimbo — como potência para desnaturalizar a função figurativa na imagem de Magritte aparece como repetição na nova imagem. Não se deixa representar - como se sua potência estivesse na negação da representação. A imagem constitui-se, assim, como um signo-acontecimento cujo regime de visibilidade se dá fora da representação ou, no mínimo, no gesto de negar as representações dominantes.

O figurativo, dirá Deleuze (2007, p. 12), “implica, com efeito, a relação entre uma imagem e um objeto que ela deve ilustrar; mas implica também a relação de uma imagem com outras imagens em um conjunto composto que dá a cada um seu objeto". Nas pinturas de Bacon, o filósofo observa como o artista conjura o caráter figurativo a fim de ruir o automatismo do espectador de inseri-lo num contexto.

$\mathrm{Na}$ imagem digital Ceci n'est pas vingt cents, um novo espaço de visibilidade parece acender, ao se abrir para outra cena que não se deixa representar. Esta é a questão central. Deleuze (2007) analisa as pinturas de Bacon para fazer uma ontologia da pintura - em que seria preciso retirar tudo o que não fosse da lógica da sensação. Talvez este também seja o melhor caminho para entender os protestos de junho de 2013 a partir da releitura digital de Ceci n'est pas vingt cents, o de retirar deste evento tudo o que é da lógica dos sentidos, para deixar emergir a repetição do que não se representa e por meio do qual o sujeito intervalar se deixa transparecer.

\section{O sujeito intervalar na tela escura}

Haveria uma relação do quadro Isto não é um cachimbo com o que Foucault (1999) observou na pintura Las meninas ${ }^{3}$, de Diego Velásquez, de 1656, ao demarcar o

3 A obra de Velásquez era primeiramente chamada de $A$ imperatriz com suas damas e um anão. No inventário de 1666, passou a se chamar Um retrato da infanta da Espanha com suas senhoras em espera 
surgimento de uma nova episteme ${ }^{4}$ ? Ou com o que Deleuze (2007) observou nos quadros de Bacon - ao analisar um novo regime de visibilidade? Trata-se de dois movimentos que podem ajudar a analisar a nova imagem, tomada como signo do acontecimento junho de 2013, para investigar uma outra cena que se abre fora da representação. O que isso significa? Foucault (1978) mostra que, entre o olhar do pintor representado na tela Las meninas, no qual olha para fora do quadro, e o olhar do espectador, um sentido será liberado - sentido que funciona num campo virtual de significação e demarca o surgimento de uma nova episteme, tal qual os discursos da mesma época ao classificar o louco na desrazão.

$\mathrm{Na}$ imagem digital dos protestos de junho de 2013, o sentido que o espectador vai liberar não é dado por um campo representacional formado a partir dos saberes constituídos num regime de visibilidade, como na representação do espelho com a imagem do rei e da rainha, mantendo-os virtualmente fora da tela e sob o qual o espectador, que se posiciona neste espaço de atualização, libera seu volume. Em vez disso, na nova imagem Ceci n'est pas vingt cents, este campo virtual no qual a representação deveria falar pelo sujeito espectador (por isso, representação da representação) começa a ruir, fazendo com que o volume a ser liberado pelo espectador tenha um sentido mais aberto do que suficientemente fechado para ordenar uma realidade. Como se viu no decorrer dos protestos de junho de 2013, apenas em seu início a pauta foi pela redução de 20 centavos na tarifa de ônibus em São Paulo; logo depois, uma multiplicidade de temas mobilizou a multidão nas ruas por todo o país.

O espelho, na pintura de Velásquez, aponta para o soberano. Na nova imagem, talvez se devesse entender a tela escura dos dispositivos móveis (smartphones, iphones, tábletes etc.) como espelho no qual a tela mostra o observador a partir da luz, mas também reflete sutilmente a imagem do próprio observador, sobretudo quando a tela escura é

e serviçais, pelo pintor da corte e camareiras do palácio Diego Velásquez. Somente depois passou a se chamar Las meninas.

4 "Por episteme entende-se, na verdade, o conjunto das relações que podem unir, em uma dada época, as práticas discursivas que dão lugar a figuras epistemológicas, as ciências, eventualmente a sistemas formalizados; o modo segundo o qual, em cada uma dessas formações discursivas, se situam e se realizam as passagens à epistemologização, à cientificidade, à formalização; a repetição desses limiares que podem coincidir, ser subordinados uns aos outros, ou estarem defasados no tempo; as relações laterais que podem existir entre figuras epistemológicas ou ciências, na medida em que se prendam a práticas discursivas vizinhas mais distintas. A episteme não é uma forma de conhecimento, ou um tipo de racionalidade que, atravessando as ciências mais diversas, manifestaria a unidade soberana de um sujeito, de um espírito ou de uma época; é o conjunto das relações que podem ser descobertas para uma época dada, entre as ciências, quando estas são analisadas no nível das regularidades discursivas." (FOUCAULT, 2013, p. 231). 
acionada. Assim, quando a luz cede espaço para a tela escura, o sujeito diante do dispositivo tem sua imagem refletida - ou seja, no intervalo de uma sequência de imagens à outra sequência, na pausa passageira, quando o sujeito desses aparelhos aciona ou aperta a opção de voltar à tela escura, sua imagem translúcida aparece. Ter-se-ia aí a caricatura de um sujeito intervalar cuja imagem é um efeito que se projeta da tela escura nos instantes de pausa. O sujeito intervalar é um sujeito da pausa, dos cortes, da ausência de imagens externas que busca ver como um estranho em seus próprios objetos.

O sujeito estaria assim subordinado ao tempo da pausa e à imagem espectral na tela escura. O sujeito contemporâneo, mais do que nunca, é intervalar, constituindo-se a partir das condições materiais da atualidade dadas pelos dispositivos e aplicativos que o lançam, sempre, para outra cena no qual ele próprio é separado do que consome. Nesse consumo incessante, há um movimento estruturante, a sequência de imagens e o intervalo que se sucede na tela escura. Trata-se do sujeito do rastro de imagens que insiste em se repetir na busca frenética por novas cenas, deparando com um espectro de sua própria cena no intervalo, quando aciona a tela escura, como se ele mesmo se percebesse nesse traço quase apagado no reflexo escuro de seu aparelho.

A identidade do sujeito intervalar é o simulacro, imagem sem modelo transcendental, apenas traços de um estranho que insiste em retornar na tela escura. Antes mesmo de entrar numa cadeia significante, aciona a luz na tela e se apaga na sucessão de imagens que virão, nos likes que dará, nos textos não lidos até o final, nos links acionados, na passagem de uma tela a outra etc.

Em outra imagem digital, publicada na Folha online, em 23 de junho de 2013, a mesma temática é apresentada em estilo de desenho carvão com duas moedas de dez centavos e, logo abaixo, Ceci n'est pas 20 centavos. Mas uma diferença altera a natureza da análise em relação à imagem anônima tomada como signo-acontecimento. Nesta, vêse a assinatura Bybia, fazendo do desenho a extensão de um autor, e, sob o qual, o jornal ancora a interpretação do leitor com a legenda: "Cartaz para dizer [sic] que a luta não é apenas pelos vinte centavos fazendo referência à obra 'Ceci n'est pas une pipe' (isto não é um cachimbo), de René Magritte" — como se pode conferir na Figura 2. 


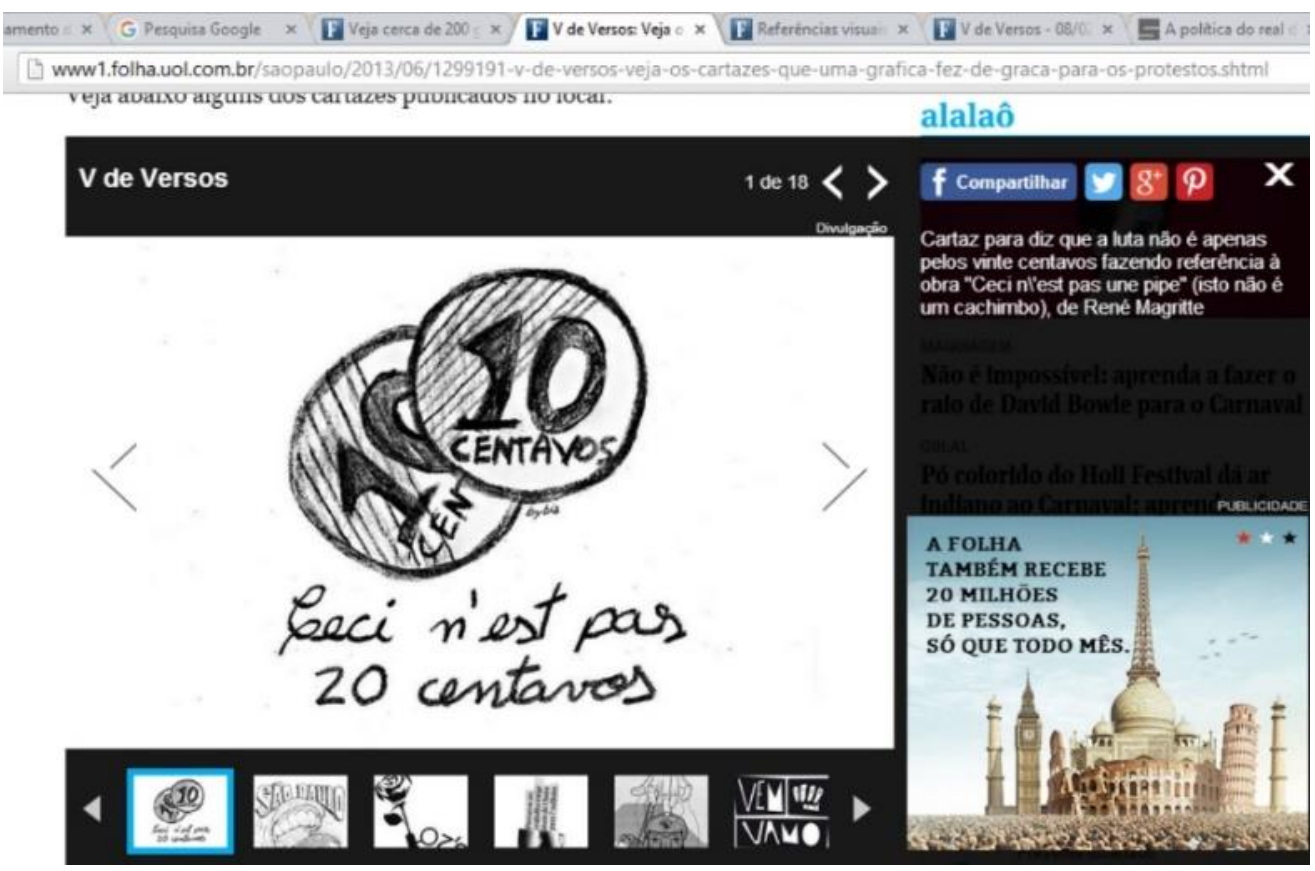

Fonte: http://zip.net/bxtpM2

Está-se diante de duas imagens digitais que fazem releituras do mesmo quadro, mas que estão em regimes de visibilidades diferentes. A primeira rompe por completo a noção de representação, implodindo a autoria, enquanto a segunda segue a lógica da representação — sob a qual um sujeito "pleno" estaria ancorado. As duas imagens não integram uma mesma série, apesar de suas semelhanças.

Em um ensaio, Guattari tocou no ponto em questão: "Não existe, de um lado, sujeito que fala 'no vazio' e, de outro, um objeto que seria falado no 'cheio"” (GUATTARI, 1988, p. 14). O plano de imanência sobre o qual o sujeito e o objeto estão implicados constitui um mesmo campo de força e, antes mesmo do sentido fabricado, funciona como causa de toda produção. Autoria não passaria de uma função nas relações de poder/saber.

No lado do internauta, uma força o mobiliza a liberar um conteúdo, sendo ele em si a emergência deste algo a mais que diz respeito ao modo como foi engendrado no processo. $\mathrm{O}$ internauta se conecta a uma teia e se excede na imagem produzida pela qual preenche um feixe de visibilidade, no gesto incessante de se atualizar a cada olhar. Não há objeto fixo que sirva de modelo, senão uma realidade que se faz ver como fabricação no momento de constituição do acontecimento. Não seria melhor dizer que o internauta se faz nesta fabricação, neste engendramento com algo a mais? O sujeito-internauta é como um rosto na areia da praia, ou um espetro na tela escura que mal se vê e num 
simples movimento se altera, mesmo que insipiente, quando a luz ambiente já é suficiente para seu desaparecimento.

\section{Dissolução do eu - ou agenciamento coletivo de enunciação}

No quadro Las Meninas, de Velásquez, Foucault (1999) observa a emergência de um olhar específico na idade clássica em que o sujeito passa a ser centralizado por outro olhar fora da cena, a representação radical. Do eu centralizado pelos discursos (representações) que criam um campo de visibilidade (representação da representação) no qual o sujeito encontrará seu centro, passa-se ao eu descentralizado em Triptico: estudos do corpo humano, do pintor Francis Bacon (1970), no qual a forma é muito mais marcada pela deformação sem centralidade. Deleuze (2007) percebe, nessa mudança, a “dissolução do eu".

O sujeito não é mais deixado fora da representação para que outra representação o centralize. Ao contrário, as pinturas de Bacon não encontram sua expressão na representação, e as cores e as linhas não fazem referências a outra representação — é com a dissolução do sujeito que Deleuze e Guattari (1997) passam a se referir a agenciamento coletivo de enunciação.

Em Cinco proposições sobre a psicanálise, publicação de $A$ ilha, o autor dirá que:

De fato, o que produz enunciados em cada um de nós, não poderá dizer um de nós, não se deve a nós enquanto sujeitos, mas a outra coisa, às multiplicidades, às massas, e às matilhas, aos povos e às tribos, aos agenciamentos coletivos que nos atravessam, que nos são interiores e que nós não conhecemos porque fazem parte do nosso próprio inconsciente. A tarefa de uma verdadeira análise, de uma análise antipsicanalítica, é descobrir esses agenciamentos coletivos de enunciação, esses encadeamentos coletivos, esses povos que estão em nós e que nos fazem falar, e a partir dos quais nós produzimos enunciados (DELEUZE, 2006, p. 347).

Os agenciamentos coletivos de enunciação são, para Deleuze, o próprio inconsciente, as vozes que falam sem que o sujeito se dê conta, porque ele próprio existe agenciando. Nesta via, o filósofo opera na crítica à psicanálise, para a qual o inconsciente seria concebido como "uma espécie de parasita da consciência" (DELEUZE, 2006, p. 345), lugar da negação e do recalcamento. Assim, o que é insuportável ao sujeito da consciência continuará como parasita, recalcado, compondo aí o teatro fantasmagórico que atormentará o sujeito. 
A fonte geradora dos sintomas na via psicanalítica, segundo Deleuze, são os desejos, sempre demais. "Para nós, ao contrário, não há nunca desejos o bastante" (DELEUZE, 2006, p. 345). A mudança se refere a um inconsciente produzido a partir dos processos de recalcamento para outra compreensão, a de que o inconsciente deve ser produzido "politicamente, economicamente e historicamente" (DELEUZE, 2006, p. 345). Entre os exemplos: “[...] quando o Homens dos lobos sonha com seis ou sete lobos, o que é por definição uma matilha, a saber, um certo tipo de grupo, Freud só pensa em reduzir esta multiplicidade, em conduzir tudo a um só lobo, que será forçosamente o pai" (DELEUZE, 2006, p. 346).

Além disso, Deleuze insere a própria psicanálise como um agenciamento coletivo de enunciação que faz operar um conjunto de enunciados próprios do capitalismo, “concernentes à castração, à falta, à família, e ela tenta fazer passar esse pequeno número de enunciados coletivos próprios do capitalismo por enunciados individuais dos próprios pacientes" (DELEUZE, 2006, p. 347).

A crítica à clínica psicanalítica se passa em não inserir o sujeito nos dispositivos de poder (para usar uma expressão de Foucault), que capturam sua subjetividade, de tal maneira que seus sintomas não se reduziriam à família, à castração que o deixa sempre em falta, mas, sim, para usar outro termo de Deleuze e Guattari (1997), a uma “máquina paranoica" que faz toda energia funcionar a serviço dela.

A análise que concerne ao filósofo francês é, a partir dos enunciados individuais, ou seja, das enunciações, levar o sujeito a descobrir os verdadeiros agenciamentos coletivos de enunciação que os produz, o que não poderia estar circunscrito somente na família ou na figura paterna, mas na máquina paranoica.

Ao final da conferência Cinco proposições sobre a psicanálise, quando Deleuze responde às perguntas da plateia, ele retoma por outros caminhos o que procurara afirmar ao dizer: "é nos grandes conjuntos paranoicos que se organizam pequenas fugas de esquizofrenia" (DELEUZE, 2006, p. 350). Para ilustrar, Deleuze cita a guerra do Vietnã como um gigantesco evento de uma máquina paranoica envolvendo um complexomilitar, mas, também, regimes de signos político e econômico que teriam a função de regular o que se poderia ver e significar da guerra.

Todo mundo diz 'bravo', exceto um pequeno número, todos os países dizem 'muito bem', isso não escandaliza ninguém. Não escandaliza ninguém, salvo um pequeno número de pessoas denunciadas de esquerdistas. Depois, eis que acontece um pequeno caso, nada muito importante, uma história de espionagem, de roubo, de política e de 
psiquiatria, entre um partido americano e outro. Há fugas. E toda a brava gente que aceita muito bem a guerra no Vietnam, que aceita muito bem essa grande maquinaria paranoica, começa a dizer: o presidente do EUA não respeita mais as regras do jogo. Uma pequena fuga esquizofrênica se implantou no grande sistema paranoico, os jornais perdem a cabeça ou fingem perdê-la. Por que não as ações na bolsa? O que nos interessa atualmente são as linhas de fuga nos sistemas, as condições nas quais essas linhas formam ou suscitam as forças revolucionárias, ou permanecem anedóticas. As probabilidades revolucionárias não consistem em contradições do sistema capitalista, mas em movimentos de fuga que o minam, sempre inesperados, sempre renovados. Renovam-nos, na medida que utilizam a palavra esquizoanálise, por confundir o esquizofrênico e o revolucionário (DELEUZE, 2006, p. 350-351).

Tome-se uma enunciação de fuga durante o acontecimento junho de 2013, quando um repórter pergunta pela identidade de uma manifestante do Movimento Passe Livre (MPL), e ela, então, responde: "eu não sou ninguém"5. Trata-se de um movimento de fuga que está na mesma linha de subjetividade da imagem Ceci n'est pas vingt cents, assim como os mais variados dizeres nos cartazes e nos discursos dos manifestantes com seus megafones, mas, desta vez, como uma enunciação esquizo-analítica que faz confundir os jornais e também o revolucionário que segue uma orientação programática. O sentido não altera o modo como até então foi trabalhado, apenas vem contribuir com o debate, fazendo ressaltar esse movimento que não se unifica numa máquina, como diz Deleuze, não "reproduza um aparelho do Estado nem de Partido" (DELEUZE, 2006, p. 352). Uma máquina de guerra não trabalha com grandes dualidades, não tem como função reproduzir uma estrutura existente para tomar o poder, mas, unicamente, continuar na fuga. A fuga é a dissolução do eu.

\section{Desagregação}

"Isto não é um cachimbo" se insere num campo nebuloso em que o enunciado talvez seja apenas traço na composição da pintura. O próprio Magritte responde: "Num quadro, as palavras são da mesma substância que as imagens" (FOUCAULT, 1988, p. 51). No mesmo período, Magritte conclui A chave dos sonhos (1930), associando

5 Citado pela primeira vez pelo filósofo Peter Pál Pelbart em artigo publicado na Folha de S. Paulo de 19 de junho de 2013. Ver: https://www1.folha.uol.com.br/paywall/signup.shtml? https://www1.folha.uol.com.br/fsp/opiniao/119566- quotanota-ai-eu-sou-ninguemquot.shtml. Acesso: 22 nov. 2016. 
livremente imagens e textos sem ligação - a arte dependeria de se libertar das regras da linguagem, ou melhor, de representar o que existe numa lógica funcional.

Nessa versão, Magritte designa a um ovo, l'acacia (a acácia); a um sapato feminino, la lune (a lua); a um chapéu masculino, la neige (a neve); a uma vela acesa, le plafond (o teto); a um copo, l'orage (a tempestade); e, por fim, a um martelo, le désert (o deserto) - como se pode observar na Figura 3.

Figura 3 - A chave dos sonhos

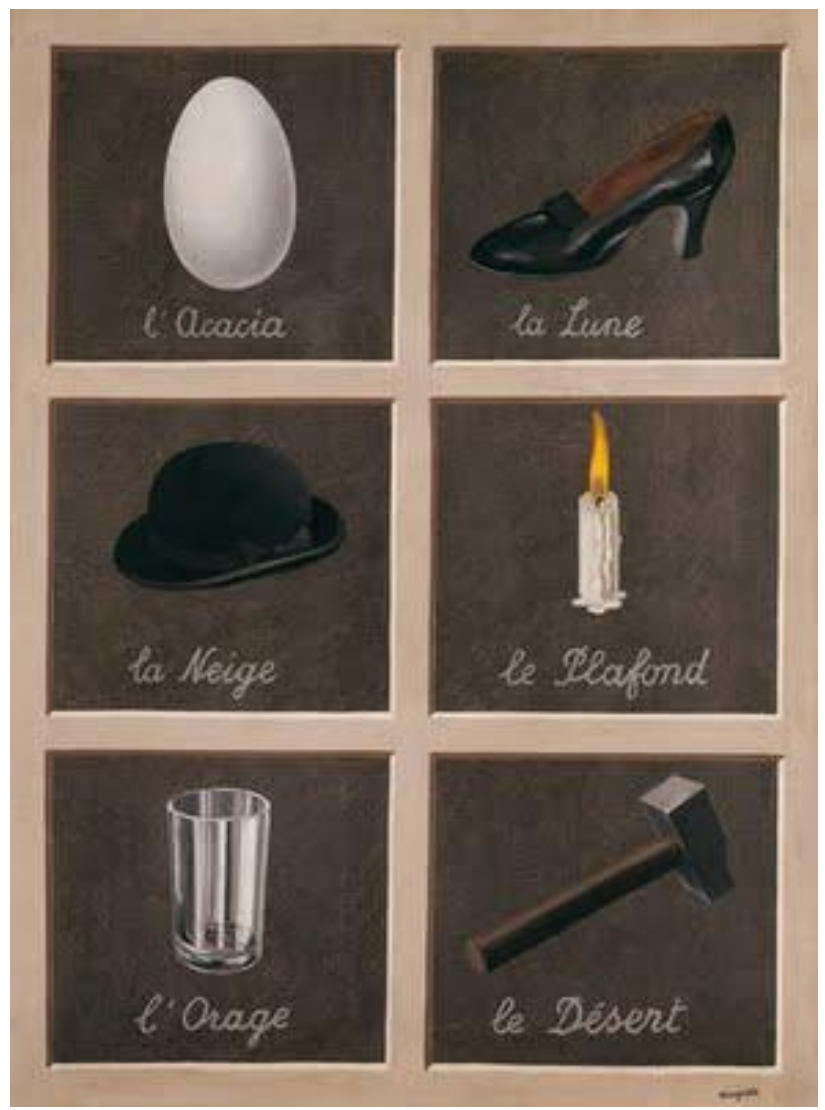

Fonte: La clef des songes, 1930 (MAGRITTE, 1998, p. 23)

A relação da forma coisa e nome são inspirações com uma das principais obras de Freud, A interpretação dos sonhos (1987) - e não é de forma gratuita. Não por acaso, "nós pertencemos à revolução cezanniana e freudiana, como lembra o filósofo francês Jean-François Lyotard” (RIVERA, 2005, p. 7). Na pintura, o "quadro não mais se compõe a partir da posição inquestionável e bem centrada de um olhar ordenador, segundo as leis da perspectiva, e assim o espaço da obra se desestabiliza" (RIVERA, 2005, p. 7). Já com a psicanálise é o sujeito desse suposto olhar ordenador que perde sua centralidade. 
Deleuze observará posteriormente que este - o da revolução cezanniana e freudiana - é o lugar de pensar o moderno: "Todas as identidades são apenas simuladas, produzindo como um 'efeito' ótico por um jogo mais profundo, que é o da diferença e da repetição" (DELEUZE, 1998, p. 16).

Esse arranjo em que algo é subtraído do quê, enquanto diferenciação, nada falta, constitui o domínio de expressão na pintura surrealista; subtraído, sub (abaixo) e traído (traição), como se a linguagem fosse uma traição. Não seria a imagem realista de um cachimbo uma traição no movimento de naturalizar a imagem no lugar do objeto? Sua potência - da linguagem - está justamente na valorização dos termos que ela junta, sem anular um ao outro.

A dissonância entre a imagem realista (que funciona por semelhança ao que faz referência) de um cachimbo com o enunciado instaura um paradoxo, produzindo desagregação da realidade. Guimarães, ao citar a leitura do quadro de Magritte feita por Foucault - quase 50 anos depois — para mostrar uma dimensão topológica de seu pensamento, comenta que o que perturba o filósofo:

é a inevitabilidade que nos faz relacionar o texto ao desenho, em que se vê o imperativo nos impossibilitando manter o olhar para além de todo deciframento possível [...]. Essa armadilha, que não é fraturada pelo vazio ao redor dos elementos do quadro, impede que a imagem e o texto caiam, 'cada um de seu lado, segundo a gravitação que lhes é própria' (GUIMARÃES, 2010, p. 21).

A "inevitabilidade que nos faz relacionar o texto ao desenho" é a mesma da imagem digital, pois a dimensão topológica que Guimarães (2010) faz ver é, ao mesmo tempo, o céu sob qual o internauta se excede neste deslizamento da imagem das moedas com o texto abaixo. Mas não se trata de só de uma imagem postada numa rede de relacionamento à outra para referir-se a algo a mais, que está fora da cena, mas sob a qual permanece obscura, com uma estranheza familiar.

\section{Representação radical}

"Uma data pode servir de referência: 1656, decreto da fundação, em Paris, do Hospital Geral" (FOUCAULT, 1978, p. 56). Há uma simetria entre o quadro Las meninas e a emergência de um modo de pensamento do século XVII que deu as condições para a criação do Hospital Geral. Como observa Safatle (s/d), ambos, a pintura e o edito do 
hospital, datam de 1656, o que leva a perceber que há, em Foucault, um gesto de fazer as escavações simbólicas (arqueologia do saber) em determinados períodos para, justamente, investigar o surgimento de uma episteme - neste caso, a episteme clássica. Em História da Loucura, as formações discursivas fizeram emergir, no século XIX, o doente mental à luz da psiquiatria, levando o louco a ser o representante da representação de um processo de ordenamento social - sendo que a ordem do discurso era enclausurar o louco, obedecendo, para o seu confinamento, à métrica da desrazão. Na passagem do louco, na idade clássica, ao doente mental, no século XIX, observa Foucault (1978, p. $35)$ :

\begin{abstract}
A loucura tornou-se uma forma relativa à razão ou, melhor, loucura e razão entraram numa relação eternamente reversível que faz com que toda loucura tenha sua razão que a julga e controla, e toda razão sua loucura na qual ela encontra sua verdade irrisória. Cada uma é a medida da outra, e nesse movimento de referência recíproca elas se recusam, mas uma fundamenta a outra.
\end{abstract}

Neste contexto, a loucura constitui-se como objeto da razão ao mesmo tempo em que a segunda se impõe como soberana ao demarcar, regular, descrever seu funcionamento e seu porvir nos campos do saber e do poder. Como observa Foucault (1978, p. 57), a “soberania quase absoluta, jurisdição sem apelações, direito sem execução contra o qual nada pode prevalecer o Hospital Geral é um estranho poder que o rei estabelece entre a polícia e a justiça, nos limites da lei: é a terceira ordem da repressão".

O ponto que se observa é a soberania do rei com um estranho poder, uma estrutura semijurídica. Na mesma episteme em formação, podia-se também ver na pintura de Velásquez o lugar vazio sobre o qual se abria, a partir do olhar do pintor, para fora do quadro, lugar primordial do rei e da rainha representados no espelho em que o espectador experimentaria a representação radical.

A dobra da própria representação é "o desaparecimento necessário daquilo que funda - daquele a quem ela se assemelha e daquele a cujos olhos ela não passa semelhança" (FOUCAULT, 1999, p. 20-21). Desaparece a semelhança como cópia nomear as coisas segundo uma lógica interna ${ }^{6}$-, assim como um modo de olhar que estabeleceria um vínculo natural entre semelhança e modelo: "os signos faziam parte das

6 Um exemplo é buscar a etimologia da palavra orquídea, que vem do grego órkhis, que significa testículo, e eidos, que, por sua vez, significa aspecto ou forma. Isto porque o caule de uma orquídea teria semelhança com um testículo. 
coisas, ao passo que no século XVII eles se tornam modos da representação" (FOUCAULT, 1999, p. 177).

Foucault (FOUCAULT, 1999, p. 20-21) observará que “o próprio sujeito — que é o mesmo - foi elidido. E finalmente livre desta relação que o aprisiona, a representação pode se oferecer como pura representação", ou seja, representação da representação. O sujeito retirado desse uso da linguagem cujo plano de expressão estabeleceria uma relação interna com a coisa referida entraria, agora, numa relação puramente arbitrária, simbólica da linguagem.

Sem centro, mas centralizado pelos discursos, o sujeito moderno passa a ser um traço sempre a se fazer pelo campo de visibilidade que se forma na representação da representação. Não seria justamente isto que se vê na pintura de Velásquez (figura 4): o que está na tela da tela representada na própria pintura? O que está faltando ao campo de visão do espectador é também o que causa a sua emergência. Onde o sujeito está retirado do campo de visão (o que o Velásquez do interior do quadro estaria pintando?) faz emergir uma nova representação (discursividade) que constituiria, para Foucault (1999), a episteme clássica. Não é o que supostamente o pintor do quadro faz na tela, que está de costas para o espectador, mas como este plano de visibilidade insere o sujeito no interior da representação, deixando-o desde o início emaranhado nesta nova episteme que vai fundar o sujeito moderno.

Figura 4 - A representação radical

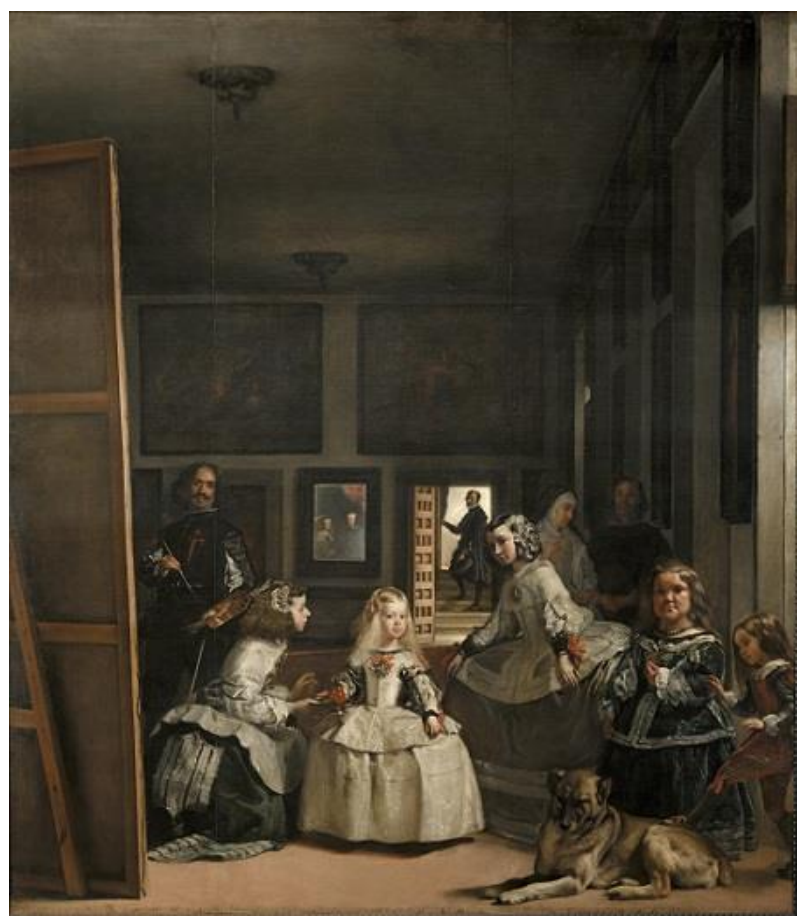

Fonte: Diego Velásquez. Las meninas, 1656. Óleo sobre tela (276-318cm). Museu del Prado, Madri, Espanha. 
Neste contexto de análise da imagem, Foucault (1999, p. 3) registra que: “O pintor está ligeiramente afastado do quadro. Lança um olhar em direção ao modelo; talvez se trate de acrescentar um último toque, mas é possível também que o primeiro traço não tenha ainda sido aplicado".

Na modernidade, o sujeito é descentralizado em relação à representação, mas é centralizado pelas formas de representação da representação (discursividades), como o louco que passa a existir como doente mental a partir dos discursos que emergem na idade clássica até o século XIX, delimitando o novo campo de visibilidade.

Na pintura, é "entre a fina ponta do pincel e o gume do olhar, [que] o espetáculo vai liberar seu volume" (FOUCAULT, 1999, p. 3). A parte cortante de uma lâmina é seu gume, assim como o fino espaço que se abre no corte. Só que a lâmina é o olhar do observador que corta e libera seu volume. O ponto para o corte é dado pelo próprio pintor na tela, que, "com o rosto ligeiramente virado e a cabeça inclinada para o ombro [...] fixa um ponto invisível, mas que nós, espectadores, podemos facilmente determinar, pois que esse ponto somos nós mesmos: nosso corpo, nosso rosto, nossos olhos" (FOUCAULT, 1999, p. 4).

Entre o visível e o invisível, o espectador encontra-se no segundo lado, no qual o espetáculo vai começar constituindo-se pela sua própria natureza, a representação radical que se forma do espaço deixado pelo olhar do pintor fixado no ponto vazio (o do sujeito), como se a pintura o olhasse.

O nó da amarração se desenvolve no "face-a-face", quando o olhar do observador encontra o olhar do pintor. E dirá Foucault (1999, p. 5): “nós, espectadores, estamos em excesso". Estaríamos, então, em excesso a partir de um lugar vazio? Afinal, tal vazio permanecerá neste "face-a-face" como espaço do que não se deixa ser preenchido, caso contrário, a tela de costas para o espectador mostraria seu anverso para revelar, daí sim, o real.

\section{Considerações}

A contemporaneidade é marcada por novas condições materiais e subjetivas, possibilitando novos arranjos, novos agenciamentos de se constituir como sujeito. Nesse tempo, os dispositivos móveis de acesso à internet e às imagens são meios pelos quais se desenvolvem novos processos de subjetivação. 
Com este artigo, foram destacados os processos que resistem aos discursos dominantes, como a imagem Ceci n'est pas vingt cents. Ao mesmo tempo, a experiência com os dispositivos móveis permitiu estabelecer a relação da tela escura com a noção de sujeito intervalar, na qual este sujeito se constitui nas pausas dos fluxos de conteúdos com os quais interage. Nos intervalos, o sujeito tem sua imagem translúcida. Intervalos efêmeros. Logo, a luz aciona as imagens em excesso e faz desaparecer o reflexo de um estranho familiar. Quando vem novamente a pausa, involuntariamente, a tela funciona como espelho de um sujeito desagregado, que se reconhece no fluxo de conteúdos consumidos, embora se veja como um estranho.

O sujeito intervalar é esta imagem frágil desenhada na areia da praia e afagada pelo vento que a deforma até seu desaparecimento completo. Entre a areia e o vento, a imagem não pode ser subtraída como única, ou haveria alguma substância além da areia e do vento? Ela, a imagem, ele, o sujeito, integram a multiplicidade. O múltiplo tratado como substância. 


\section{Referências}

DELEUZE, Gilles. Cinco proposições sobre a psicanálise. In: DELEUZE, Gilles. A ilha deserta. São Paulo: Iluminuras, 2006.

DELEUZE, Gilles. Francis Bacon: lógica da sensação. Rio de Janeiro: Zahar, 2007.

DELEUZE, Gilles. Diferença e repetição. Rio de Janeiro: Graal, 1988.

DELEUZE, GILLES; GUATTARI, Félix. Mil platôs: capitalismo e esquizofrenia. Vol. 2. Rio de Janeiro: Ed. 34, 1997.

FOUCAULT, Michel. Arqueologia do saber. Rio de Janeiro: Forense Universitária, 2013.

FOUCAULT, Michel. As palavras e as coisas. São Paulo: Martins Fontes, 1999.

FOUCAULT, Michel. História da loucura. São Paulo: Perspectiva, 1978.

FOUCAULT, Michel. Isto não é um cachimbo. Rio de Janeiro: Paz e Terra, 1988.

FREUD, S. (1900). A interpretação dos sonhos. In: Edição standard brasileira das obras psicológicas completas de Sigmund Freud. 2.ed. Rio de Janeiro: Imago, 1987. v. 4,5 .

GUATTARI, Félix. O inconsciente maquínico. Ensaios de equizo-análise. São Paulo: Papirus, 1988.

GUIMARÃES, Rodrigo. Espaços formais de pensamento: topologias do literário e do filosófico. In: Poros, Uberlândia, v. 2, p. 3, p. 17-36, 2010.

RIVERA, Tania. Arte e Psicanálise. Rio de Janeiro: Jorge Zahar, 2005.

SAFATLE, Vladimir. Curso de introdução à experiência intelectual de Gilles Deleuze. Em direção à Diferença e Repetição. 2012. Disponível em:

https://www.passeidireto.com/arquivo/24526009/curso-introducao-a-experienciaintelectual-de-deleuze. Acesso em: 06 mar. 2019. 


\section{Para citar essa obra:}

VENERA, José Isaías; Por uma teoria do sujeito intervalar na experiência com a tela escura. In: RUA [online]. Volume 25, número 2 - p. 505-521 - e-ISSN 2179-9911 - novembro/2019. Consultada no Portal Labeurb - Revista do Laboratório de Estudos Urbanos do Núcleo de Desenvolvimento da Criatividade.

http://www.labeurb.unicamp.br/rua/

Capa: Figura 1: Imagem que circulou em diferentes redes sociais da internet.

\section{Laboratório de Estudos Urbanos - LABEURB}

Núcleo de Desenvolvimento da Criatividade - NUDECRI

Universidade Estadual de Campinas - UNICAMP

http://www.labeurb.unicamp.br/

Endereço:

LABEURB - LABORATÓRIO DE ESTUDOS URBANOS

UNICAMP/COCEN / NUDECRI

CAIXA POSTAL 6166

Campinas/SP - Brasil

CEP 13083-892

Fone/ Fax: (19) 3521-7900

Contato: http://www.labeurb.unicamp.br/contato 